\title{
Individual's awareness of healthy lifestyle: A cross sectional study of a rural community in Kedah, Malaysia
}

Fernandez $\mathrm{K}^{1}$, Kharkwal $\mathrm{KC}^{2}$, Afrose $\mathrm{T}^{3 *}$, Habib $\mathrm{N}^{4}$, Das $\mathrm{S}^{5}$

*Corresponding author:

Dr. Tahmina Afrose, MBBS, MPH, Lecturer, Department of Community Medicine, Faculty of Medicine, AIMST University, Semeling 08100, Bedong, Kedah, Malaysia.

Email: drtakeya@gmail.com ORCID

Information about the article:

Received: May 22, 2019

Accepted: Dec. 18, 2019

Published online: Dec 22, 2019

\section{Cite this article:}

Fernandez K, Kharkwal KC, Afrose T, Habib N, Das S. Individual's awareness of healthy lifestyle: A cross sectional study of a rural community in Kedah, Malaysia. Journal of Biomedical Sciences. 2019;6(2):12-18

\section{Publisher}

Nepal Health Research Society, Bahundhara -6, Gokarnesowor Municipality, Kathmandu, Nepal eISSN 2382-5545, ISSN 2676-1343 (Print)

(C) The Author(s). 2019

Content licensing: CC BY 4.0

\begin{abstract}
Background

Healthy lifestyle practices play a key role in disease prevention and control of any chronic illness and disability. This study aims to identify the role of individual's awareness towards a healthy life and well-being in a rural community
\end{abstract}

\section{Material and methods}

This descriptive cross-sectional study was conducted by using structured questionnaire at a village, Kedah state, Malaysia on 2018.

\section{Results}

The study revealed that among 120 respondents the mean $\pm \mathrm{SD}$ age of respondents was $24 \pm 16.32$ years. All the respondents were Muslim. The mean \pm SD weight of respondents was $66.07 \pm 14.353$ kilogram. Study revealed that no participant reported drinking alcohol within the last month. 91 (76.6\%) of the respondents were non-smoker. $42(35 \%)$ respondents reported daily consumption of fruits. $86(71.67 \%)$ respondents reported moderate to vigorous physical activities for 30 minutes per day. Regarding comorbidity status, 60 (49.9\%) was not suffering from any form of illness during the study period. This study found the significant association between the BMI and smoking habit with co-morbidity $(\mathrm{p}<0.000)$.

\section{Conclusion}

Majority of the participants of this study was health conscious and had positive health-related behaviour. The effective behavioral changes less likely to happen unless the individual's awareness and motivation towards a healthy life is decreased.

\section{Keywords}

Awareness, chronic illness, community, health-related behaviours, physical activity 


\section{Introduction}

According to World Health Organization (WHO), health is defined as a "state of complete physical, mental and social well-being and not merely the absence of disease or infirmity" [1, 2]. Health-related behaviour can affect individual's health condition, either positively or negatively [3]. Common health -related behaviours are diet, physical exercise, smoking, alcohol consumption, safety practices and health screening examination. Among these, healthy diet and regular physical exercise have been given more priority because of their positive impact on health by disease prevention, increasing longevity of life and improving psychological wellbeing $[4,5]$. Sedentary lifestyle is one of the major key factors for increased Noncommunicable disease (NCDs) in Malaysia [6].

Healthy lifestyle is associated with both short term health benefits such as feeling well and energetic and also longterm health benefits by reducing the risk of developing certain chronic diseases such as cardiovascular disease, diabetes, obesity, arthritis and even cancer [7].

The key determinants of health are the socio-economic environment, the physical environment and the individuals' behaviour. Among those, the individual behavioral characteristics and socio-economic factors play a crucial role in human life. The main factors that determine whether people are healthy or unhealthy includes gender, education, income, occupational status, social and physical environment, individual health practices and adaptation, capability and the availability of health care services [8].

Worldwide the two major health issues are malnutrition and disease. Malnutrition includes under-nutrition and overnutrition or obesity. The most common diseases that are associated with early death worldwide include cardiovascular disease (CVD) (e.g. ischemic heart disease), gastroenteritis, neonatal disorders, chronic obstructive pulmonary disease (COPD), lower respiratory tract infections (LRTI) and road traffic accidents (RTA) which are associated with more than 1 million deaths each year [9].

Unhealthy lifestyle is associated with poor health which includes unhealthy diet, smoking habit, excessive alcohol consumption and physical inactivity. Healthy diet such as certain plant and animal-based foods are required to maintain individual's health. The food guide pyramid is a pyramid-shaped guide divided into different sections based on the recommended intake of each food group such as carbohydrate, protein, fat, fruits and vegetables and other nutrient components of food so that everybody can follow a balanced diet. From the top to the bottom of the food pyramid, the size of each food group becomes larger showing that an individual should eat less of the foods at the top of the pyramid compared to the foods at the base of the pyramid [10].

Regular physical exercise is associated with increased longevity of life by reducing the risk factors of chronic diseases. Regular physical exercise has a lot of health benefits such as it lowers the risk of heart attack by lowering the blood pressure and blood cholesterol level, it reduces the risk of type- 2 diabetes, osteoporosis and certain cancers and is associated with better weight management. Besides these positive health outcomes regular physical exercise is also giving a perception of feel good factor with improving sleeping patterns which help to eliminate depression of an individual. Researchers recommended at least 30 minutes moderate to vigorous physical activities daily [11].

It is the practices of taking action to improve one's health. These personal practices include getting enough sleep, maintaining proper nutrition, regular exercise, quitting smoking, avoiding excessive consumption of alcohol, maintaining social support, finding hobbies like gardening, drawing, keeping the mind sharp and having a positive attitude and maintaining a spiritual practice such as using prayer or meditation which has been shown as a major stress reliever. Self-care practices and healthy behaviours can prevent or minimize the effects of a disease [12].

Malaysia has been identified as a highest obesity problem country in South East Asia and sixth in Asia and sedentary lifestyle is the leading cause behind this [13]. According to the report from Ministry of Health Malaysia, the principal cause of morbidity and mortality among Malaysian population includes coronary heart disease, type-II diabetes mellitus, cancer, mental illness and even disease of pulmonary circulation which are associated by not being active [14].

\section{Material and methods}

\section{Study Period}

The duration of this study was from the $1^{\text {st }}$ April 2018 until 30 April 2018.

\section{Study design and the participants}

This descriptive cross-sectional study was conducted at a village 'Kampung Batu Hampar' in Kedah state of Malaysia. The study was performed by the MBBS Batch22, Year-3, Group-B students of AIMST University, Malaysia under supervision. The study population was one hundred and twenty which were randomly selected. Structured questionnaire which was adapted from WHO manual was delivered among the respondents. The questionnaire was pre-tested. The questions used in the questionnaire were related to socio-demographic characteristics and lifestyle and personal health behaviors of the respondents. The purpose of the study was explained to the study respondents and the verbal consent was secured from individual respondent. Confidentiality was insured by not including names or other identifiers in the data collection.

\section{Data collection}

The collected data include socio-demographic details such as gender, age in years, religion, marital status etc. Physical 
characteristics (height and weight) were also measured. Body mass index (BMI) was calculated from the weight and height. BMI $(\mathrm{kg} / \mathrm{m} 2)$ was categorized as normal weight $(18.5 \leq \mathrm{BMI}<24)$, overweight $(24 \leq \mathrm{BMI}<28)$, and obese (BMI $\geq 28)$ using the WHO recommendations [15]. Occupation, education level, number of family members and income.

The collected data include lifestyle and personal health behavior details such as alcohol consumption, smoking status, numbers of cigarettes per day, fruits consumption, types of water supply, practicing water purification methods, regular exercise for 30 minutes per day, knowledge and practice of food pyramid, meals per day, skipping meals and its frequency, food preference, consuming junk food, total fluid intake, caffeinated drinks intake and diseases suffered.

\section{Inclusion criteria}

Among the villagers at any age, both male and female including the children, who were willingly to participate, has been included in this study.

\section{Exclusion Criteria}

People who were severely ill and not able to communicate and the children with disability were excluded from the study.

\section{Sample size calculation}

Random sampling was done to obtain the study sample. The formula that was used for calculation of the required Sample size is: $\mathrm{n}=\mathrm{Z} 2 \mathrm{P}(1-\mathrm{P})$ / $\mathrm{d} 2, \mathrm{n}=$ sample size $\mathrm{Z}=\mathrm{Z}$ statistic for a level of confidence (1.96 for level confidence of $95 \%) \mathrm{P}=$ expected prevalence or proportion (0.2), $\mathrm{d}=$ precision (0.05). Using population correction formula and adding $10 \%$ non-response rate the sample size was 120 . Sample was selected by convenient sampling method.

\section{Data management and statistical analysis}

Data was checked for completeness and were entered into Epidata 3.1 version and exported to SPSS 22.0 version for further analysis.

\section{Outcome variable}

The main outcome variable was individual's healthy life and wellbeing and comorbidity (diabetes mellitus/ hypertension/bronchial asthma/heart disease/other common illness/nil) after consuming healthy foods and involving regular physical activities.

\section{Explanatory variables}

The socio-demographic variables and the variables related to lifestyle and personal health behaviors have been described as individual levels. Factors which were taken into consideration at individual level were gender, BMI $(\mathrm{kg} / \mathrm{m} 2)$, smoking status, knowledge of food pyramid, regular exercise (30 minutes per day) and co-morbidity (diabetes mellitus/hypertension/bronchial asthma/heart disease /other/nil).

\section{Ethical committee approval}

This study was carried out by the MBBS Year-3 Batch-22 students of AIMST University under their community medicine posting is part of the community diagnosis module. This is part of the AIMST University curriculum and annually each batch carries out a survey at a different village in the region. The village is selected after the village head agrees to the students carrying out a survey in their locality. Consent was taken from the parents of children below 18 years. Confidentiality was insured by not including names or other identifiers in the data collection tool.

\section{Results}

Table - 1 showing the socio-demographic characteristics of study subjects. The total number of respondents was 120 . The mean \pm SD age of respondents was $24 \pm 16.32$ years. Among them about $32.5 \%$ of the respondents were in the range of 1 to 19 years old, $33.33 \%$ were in the range of 20 to $39,20.83 \%$ were in the range of 40 to $59,11.67 \%$ were in the range of 60 to 79 and $1.67 \%$ were above 80 years old. And all of them were Muslim. Among the respondents male and female were $50.8 \%$ and $49.2 \%$ accordingly. A large percentage of the participants were married (80\%).

\begin{tabular}{|c|c|c|c|}
\hline \multicolumn{4}{|c|}{ Table 1: Socio-demographic characteristics, $(N=120)$} \\
\hline & & n (\%) & $95 \%$ CI \\
\hline \multirow[t]{3}{*}{ Gender } & Male & $61(50.8)$ & $(41.86,59.74)$ \\
\hline & Female & $59(49.2)$ & $(40.26,58.14)$ \\
\hline & $1-19$ & $39(32.5)$ & $(24.12,40.88)$ \\
\hline \multirow[t]{5}{*}{ Age (years) } & $20-39$ & $40(33.33)$ & $(24.9,41.76)$ \\
\hline & $40-59$ & $25(20.83)$ & $(13.56,28.1)$ \\
\hline & $60-79$ & $14(11.67)$ & $(5.93,17.41)$ \\
\hline & $>80$ & $2(1.67)$ & $(-0.62,3.96)$ \\
\hline & Islam & $120(100)$ & $(100,100)$ \\
\hline \multirow[t]{2}{*}{ Religion } & $\begin{array}{l}\text { Others (Buddha } \\
\text { Hindu, Christian) }\end{array}$ & $0(0)$ & \\
\hline & Single & $13(10.8)$ & $(5.25,16.35)$ \\
\hline Marital & Married & $96(80.0)$ & $(72.84,87.16)$ \\
\hline \multirow[t]{3}{*}{ status } & $\begin{array}{l}\text { Separated } \\
\text { /Divorced }\end{array}$ & $1(00.8)$ & $(-0.79,2.39)$ \\
\hline & Widow(er) & $10(8.4)$ & $(3.44,13.36)$ \\
\hline & $<18.5$ & $4(3.30)$ & $(0.1,6.5)$ \\
\hline BMI & 18.5 to $<24$ & $54(45)$ & $(36.1,53.9)$ \\
\hline \multirow{2}{*}{$(\mathrm{kg} / \mathrm{m} 2)$} & 24 to $<28$ & $42(35)$ & $(26.47,43.53)$ \\
\hline & $\geq 28.0$ & $20(16.70)$ & $(10.03,23.37)$ \\
\hline \multirow[t]{3}{*}{ Occupation } & Unemployed & $70(58.3)$ & $(49.48,67.12)$ \\
\hline & Employed & $50(41.7)$ & $(32.88,50.52)$ \\
\hline & Primary & $49(40.8)$ & $(32.01,49.59)$ \\
\hline Education & Secondary & $55(45.8)$ & $(36.89,54.71)$ \\
\hline \multirow[t]{2}{*}{ Level } & Tertiary & $8(6.7)$ & $(2.23,11.17)$ \\
\hline & Nil & $8(6.7)$ & $(2.23,11.17)$ \\
\hline Number of & $0-3$ & $41(34.1)$ & $(25.62,42.58)$ \\
\hline Family & $4-7$ & $68(56.7)$ & (47.83\%, 65.57) \\
\hline Members & $>8$ & $11(9.2)$ & $(4.03,14.37)$ \\
\hline \multirow{3}{*}{ Income } & $<$ RM1000 & $46(38.3)$ & $(29.6,47)$ \\
\hline & RM1001-5000 & $71(59.2)$ & $(50.41,67.99)$ \\
\hline & >RM5001 & $3(2.5)$ & $(-0.29,5.29)$ \\
\hline
\end{tabular}


The mean \pm SD weight of respondents was $66.07 \pm 14.35$ kilogram. In terms of BMI, $45 \%$ respondents were within normal range, $35 \%$ were overweight and $16.70 \%$ were found as obese (Figure-1). Most of them had primary (40.8\%), and secondary (45.85\%) education. Among the respondents $58.3 \%$ were unemployed and $41.7 \%$ were employed. Average monthly income for 46 (38.3\%) of the respondents was less than 1000 Ringgit, for 71(59.2 \%) of them was 1001 to 5000 Ringgit and 2.5\% of them had more than 5000 Ringgit.

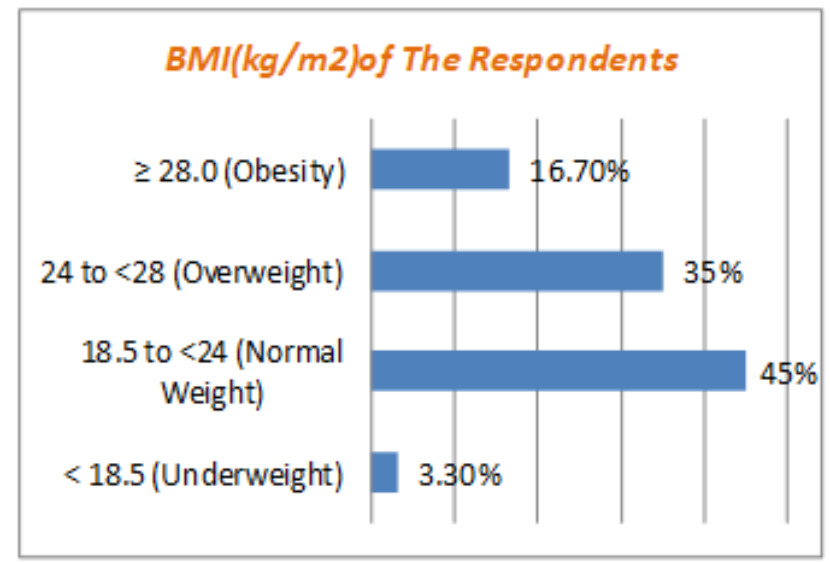

Figure-1: BMI (kg/m2) of the Respondents

Table 2 represented lifestyle and personal health behavior data. In this study no participant reported drinking alcohol within the last month. In terms of smoking status, about $23.4 \%$ were habituated to smoking whereas majority (76.6\%) were non-smoker. 35\% of the participants reported daily consuming of fruits whereas $30.8 \%$ used to eat fruits $>3$ times a week. About $98.4 \%$ respondents having the pipe water supply. Regarding water purification methods majority (53.3\%) of the respondents were practicing boiling method at household level whereas $27.5 \%, 18.3 \%$ and $0.8 \%$ were practicing filtration, combined boiling, filtration and chemical methods, respectively (Table-2).

During their leisure time, $71.67 \%$ respondents reported for moderate to vigorous physical activities for 30 minutes per day. Study showed majority (75.8\%) had a basic knowledge of Food Pyramid. Among them 50.55\% were applying this knowledge during their food choice. Regarding food habit $72.5 \%$ respondents were habituated of taking 3 times meal per day. 34.2\% respondents used to skip meals among which $41.55 \%, 48.8 \%$ and $9.7 \%$ used to skipping meals once a week, 2-3 times a week and $>3$ times a week respectively. $85.9 \%$ preferred home cooked food whereas $14.1 \%$ used to like restaurant food. In term of consuming junk food $8.3 \%, 27.5 \%, 23.3 \%$ of the respondents were taking daily, $>3$ times a week and $<3$ times a week but majority (40.8\%) of them were not like to take junk food.

In term of daily intake of fluid, majority (59.2\%) of the respondents were taking $>1000 \mathrm{ml}$ of fluid per day whereas $34.2 \%$ and $6.7 \%$ respondents were taking $500-1000 \mathrm{ml}$ and
$<500 \mathrm{ml}$ of fluid daily. The respondents reported that $35.8 \%$ of them used to take caffeinated drink daily whereas $15 \%$ were taking $>3$ times a week, $20.8 \%$ were taking $<3$ times a week. $28.3 \%$ respondents were not taking any caffeinated drink.

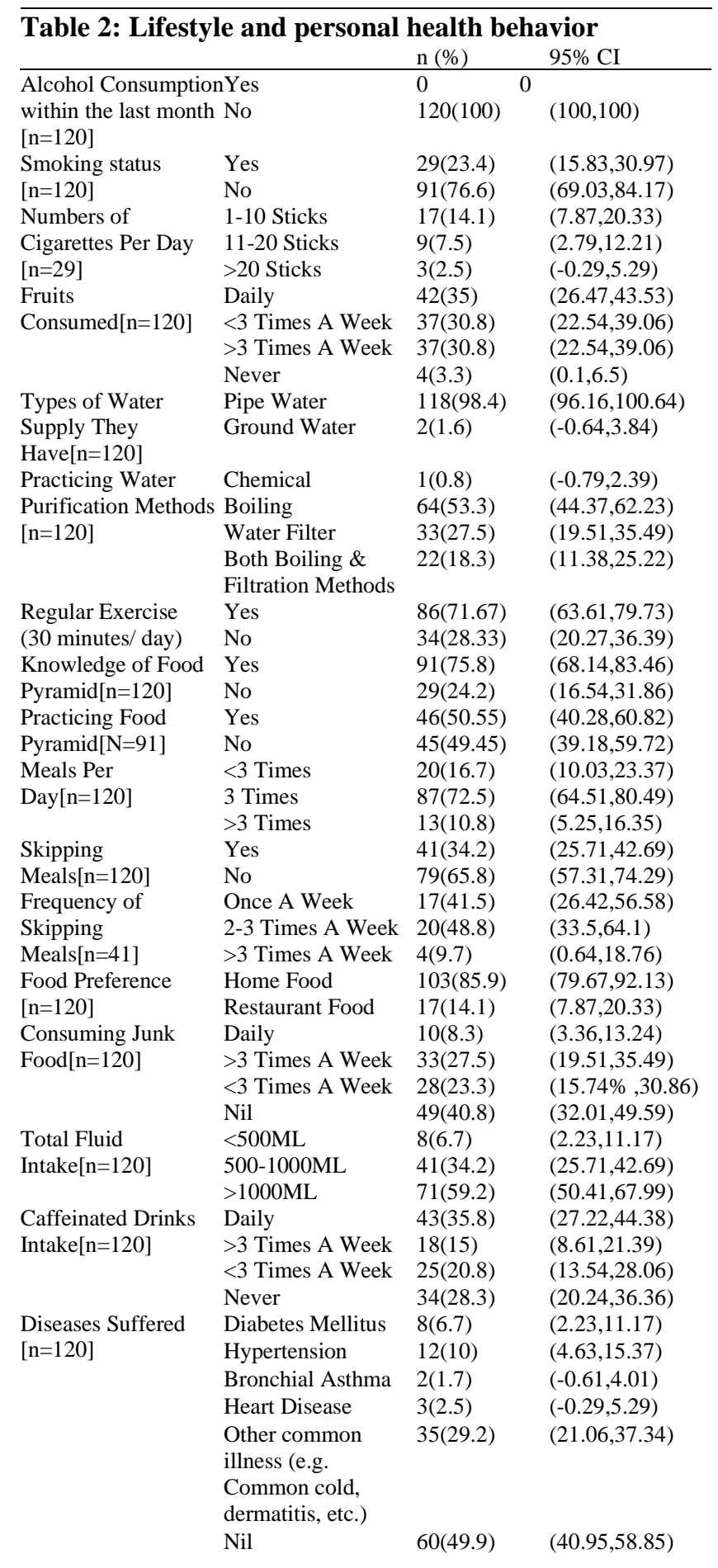


JBS 2019;6(2):12-18

Table 3: Association between gender with knowledge of food pyramid, physical exercise with BMI, smoking status with co-morbidity

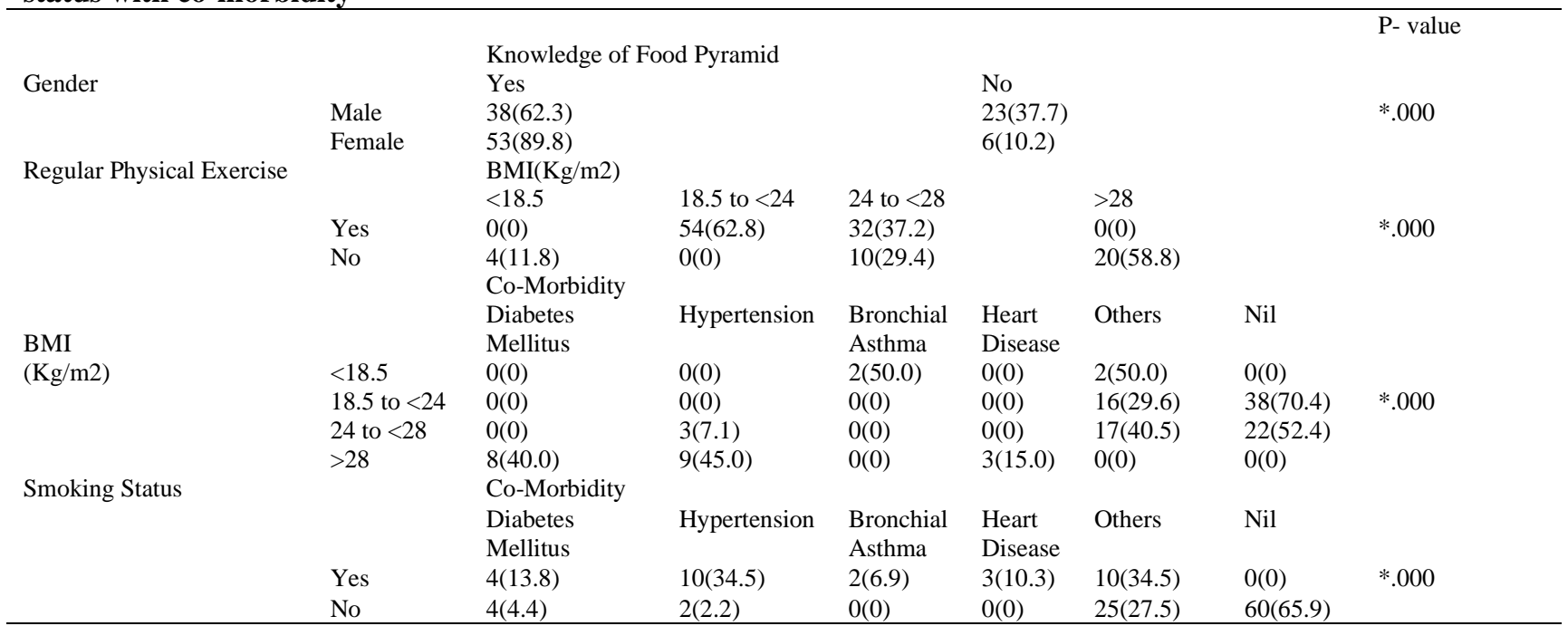

${ }^{*} \mathrm{p}<0.05$, statistically significant

Regarding co-morbidity status $6.7 \%$ were suffering from diabetes mellitus, $10 \%$ were suffering from hypertension, $1.7 \%$ were suffering from bronchial asthma, $2.5 \%$ were suffering from heart disease, 29.2\% were suffering from other common illness (e.g. common cold, dermatitis, etc.) and $49.9 \%$ were not suffering from any form of illness during the study periods (Table-1), (Figure-2).

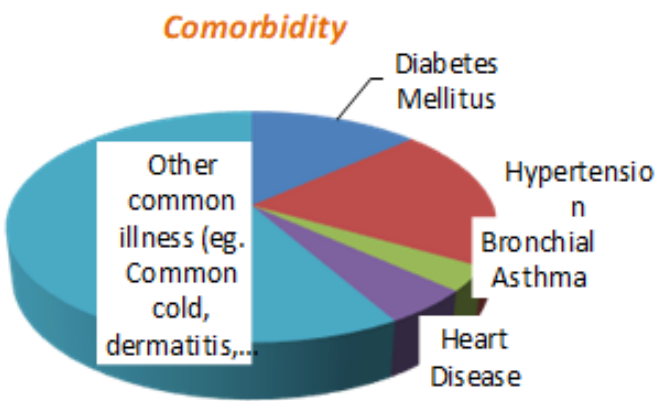

Figure-2: Distribution of the co-morbidity of the respondents

This study revealed that females are more aware about the concept of food pyramid compare to male. This study also found the significant association between regular physical exercises and the BMI $(\mathrm{p}<0.000)$, between BMI with comorbidity $(\mathrm{p}<0.000)$ and smoking status with co-morbidity $(\mathrm{p}<0.000)$. (Table-3)

\section{Discussion}

\section{Socio-demographic factor and co-morbidity}

This study showed that half of the respondents were overweight and obese who were suffering from diabetes, hypertension, heart disease and some other common illness. According to the report of Malaysia Diabetic Association, most of the type-II diabetic patient are overweight [16]. Several studies in Malaysia revealed the significant association between obesity and comorbidity with hypertension and diabetes $[6,17]$.

Most of the female respondents were aware of food pyramid as well as practicing their relevant knowledge to their food selection. This may be the region that almost half of the respondents were not suffering from any kind of illness. One study in Malaysia found that $45 \%$ adults were not following a healthy lifestyle because of their unhealthy dietary food habits and sedentary lifestyles and those people were suffering with several physical illnesses [18].

\section{Personal health behaviors and co-morbidity}

This study showed that majority of the respondents was involved in regular physical activities. Several studies in Malaysia revealed the inverse association between physical activity to the risk of overweight/obesity and they recommended to practice of moderate to vigorous-intensity physical activity. One study found the higher incidence of obesity and non-communicable diseases which were strongly associated with sedentary lifestyles and they encouraged the active lifestyle among the population [19]. This might be the reason for this studies that most of the respondents who were involving in active physical activities having normal BMI and were not suffering from any noncommunicable diseases.

This study showed that most of the respondents were nonsmoker. One study conducted in Malaysia showed the prevalence of tobacco use declined slightly whereas the use of smokeless tobacco products such as e-cigarettes has been increased significantly from 2011. Exposures of nonsmoker to second-hand smoke were also identified to be more than $48.8 \%$ [20]. 
Some studies recommended that behavioral interventions should be targeted to both the healthy diet and regular physical activities for the betterment of life and to prevent overweight and obesity [21, 22]. This study showed that most of the respondents were practicing a healthy lifestyle including the regular physical activities and near about half of them were not suffering from any chronic diseases. Practicing healthy lifestyle may be the reason behind their wellness.

\section{Conclusion}

Evidence-based practices of healthy behaviour are very crucial for disease prevention and control and individual wellbeing. Behavioral modification is the first step to improve healthy dietary practices. Further studies are required on the same field to find out the new key issues for a sustainable healthy life in a community.

\section{Abbreviations}

Body Massa Index (BMI), cardiovascular disease (CVD), chronic obstructive pulmonary disease (COPD), ischemic heart disease (IHD), lower respiratory tract infections (LRTI), non-communicable diseases (NCDs), road traffic accidents (RTA), world health organization (WHO)

\section{Authors' contribution}

KF designed the study, drafted the manuscript and revised it. KF collected the data along with the students. HN has participated in the language editing along with KF. TA participated in statistical analysis, interpreted the data, and revised the manuscript. KF, HN and TA critically revised the manuscript. All the authors approved the final document.

\section{Competing interests}

There is no conflict of interest among authors arising from the study.

\section{Acknowledgments}

We thank all the participants who took part in this study, the MBBS Year-3 students of AIMST University who were actively engaged in data collection and statistical data analysis

\section{Limitation and future scope of the study}

The sample size of the study was less. Participants in this rural area may not be representative of the whole Malaysian population. A multi centric study with higher sample size will give better conclusion about individual's awareness towards a healthy life in a community. This study was based on the research carried out in a rural community in Malaysia. A multi centric based research with high sample size would be beneficial to assess individual's healthy behaviours and awareness in relation to a betterment of life

\section{Publisher's Note}

NHRS remains neutral with regard to jurisdictional claims in published maps and institutional affiliations.

The publisher shall not be legally responsible for any types of loss, actions, claims, proceedings, demand or costs or damages whatsoever or howsoever caused arising directly or indirectly in connection with or arising out of the use of this material.

\section{Author information}

${ }^{1}$ Prof. (AIR CMDE) Kevin Fernandez Vsm, MBBS MD DPH DIH MNAMS FISCD FIPHA, Professor, Unit Head, Community Medicine

${ }^{2}$ Kailash C Kharkwal, MBBS, MD Obstetrics \& Gynaecology, Unit Head of Department of Obstetrics and Gynaecology.

${ }^{3}$ Dr. Tahmina Afrose, MBBS, MPH, Lecturer, Department of Community Medicine

${ }^{4}$ Dr. Nasrin Habib MBBS, M. Phil MPH, Senior Lecturer, Department of Physiology, Faculty of Medicine, Quest International University Perak (QIUP) City Campus, No.227, Plaza Teh Teng Seng (Level 2), Jalan Raja Permaisuri Bainun, 30250 Ipoh, Perak Darul Ridzuan, Malaysia

${ }^{5}$ Dr. Suprava Das, Senior Lecturer, MBBS, M.Phil (Pharmacology), Department of Pharmacology

${ }^{1-3}$, ${ }^{5}$ Faculty of Medicine, AIMST University, Semeling 08100, Bedong, Kedah, Malaysia.

\section{References}

1. World Health Organization. Constitution of the World Health Organization as adopted by the International Health Conference, New York, 1922 June 1946; signed on 22 July 1946 by the representatives of 61 States (Official Records of the World Health Organization, no. 2, p. 100) and entered into force on 7 April 1948. In Grad, Frank P. (2002). "The Preamble of the Constitution of the World Health Organization". Bulletin of the World Health Organization. 80(12):982.

2. World Health Organization. (2006). Constitution of the World Health Organization - Basic Documents, Forty-fifth edition, Supplement, October 2006.

3. James F. Reducing Disability in Older Age. JAMA: the journal of the American Medical Association. 2003;288. 3164-6. DOI: https://doi.org/10.1001/jama.288.24.3164

4. Fishbein M, Triandis HC, Kanfer FH. Factors influencing behavior and behavior change. In Baum A, Revenson TA Singer JE (Eds.). Handbook of health psychology, 2001. (pp. 3-18). Mahwah, NJ Google Scholar: Lawrence Erlbaum Associates. 
JBS 2019;6(2):12-18

https://pdfs.semanticscholar.org/605e/ae1a67ea4c7 9f4a6bacb71020065ca72e58e.pdf

5. Hage SM, Romano JL, Conyne, RK, Kenny M, Matthews C, Schwartz JP et al. Best Practice Guidelines on Prevention Practice, Research, Training, and Social Advocacy for Psychologists. The Counseling Psychologist. 2007;35(4):493566.

DOI: https://doi.org/10.1177/0011000006291411

6. Mazlina Mansor, Nor Zalina Harun. Health Issues and Awareness, and the Significant of Green Space for Health Promotion in Malaysia. Science Direct. Procedia - Social and Behavioral Sciences 153 (2014)209-20.

DOI: https://doi.org/10.1016/j.sbspro.2014.10.055

7. Carmody $\mathrm{T}$ Health-related behaviours: Common factors. In S. Ayers, A. Baum, C. McManus, S. Newman, K. Wallston, J. Weinman, et al. (Eds.), Cambridge Handbook of Psychology, Health and Medicine. 2007. pp. 102-109. Cambridge: Cambridge University Press.

DOI:

https://doi.org/10.1017/CBO9780511543579.023

8. World Health Organization. Salt reduction and iodine fortification strategies in public health: report of a joint technical meeting convened by the World Health Organization and The George Institute for Global Health in collaboration with the International Council for the Control of Iodine Deficiency Disorders Global Network, Sydney, Australia, March 2013.

9. Institute for Health Metrics and Evaluation (IHME). Findings from the Global Burden of Disease Study 2017. Seattle, WA: IHME, 2018

10. Ministry of Health (2010). National Coordinating Committee on Food and Nutrition . Recommended Nutrient Intakes For Malaysia (RNI). A Report of the Technical Working Group on Nutritional Guidelines. http://nutrition.moh.gov.my/wpcontent/uploads/2017/05/FA-Buku-RNI.pdf

11. Farhud DD. Impact of Lifestyle on Health. Iranian journal of public health, 2015;44(11):1442-4.

12. Murphy LR. Stress Management in Work Settings: A Critical Review of the Health Effects. American Journal of Health Promotion. 1996;11(2):112-35. DOI: https://doi.org/10.4278/0890-1171-11.2.112

13. National Health and Morbidity Survey (2011). Fact Sheet 2011. Ministry of Health Malaysia, Retrieved December 1, 2019, from the url www.moh.gov.my/images/../nhms\%2011\%20fact \%20sheet.pdf .

14. Ministry of Health Malaysia (2011). Annual report Ministry of Health Malaysia 2011. Retrieved Dec. 1, 2019, from the url http://www.moh.gov.my

15. World Health Organization. The WHO STEP wise approach to surveillance of noncommunicable diseases (STEPS) Geneva: World Health Organization; 2003.

16. Malaysia Diabetes Association (2006), Retrieved July 24, 2012, accessed on 1.12.19 from the URL http://www.diabetes.org.my/article.php

17. GR Letchuman, WM, Wan Nazaimoon WB. Wan Mohamad LR Chandran GH. Tee, H. Jamaiyah, M. R. Isa, H. et al. Prevalence of diabetes in the Malaysian National Health Morbidity Survey III 2006. Med J Malaysia. 2010 Sep; 65(3): 180-186. DOI: https://doi.org/10.1016/j.sbspro.2014.10.055

18. Chan YY, Lim KK, Lim KH, The CH, Kee CC, Cheong SM et al. Physical activity and overweight/obesity among Malaysian adults: findings from the 2015 National Health and morbidity survey (NHMS). BMC Public Health. volume 17, Article number: 733 (2017). DA. 2017/09/21

DOI: https://doi.org/10.1186/s12889-017-4772-z

19. Cai Lian T, Bonn G, Si Han Y, Chin Choo Y, Chee Piau W. Physical Activity and Its Correlates among Adults in Malaysia: A Cross-Sectional Descriptive Study. PLoS ONE. 2016;11(6): e0157730.

DOI: https://doi.org/10.1371/journal.pone.0157730

20. Muhammad Fadhli Mohd Yusoff. Institute for Public Health. National Health and Morbidity Survey 2015 National Health And Morbidity Survey 2015 Ministry of Health Malaysia. NonCommunicable Diseases, Risk Factors \& Other Health Problems VolumeII (NMRR -14-106421877). Vol II:Non-Communicable Diseases, Risk Factors and Other Health Problems. National Institutes of Health, Ministry of Health Malaysia, 2015. Published: 26 March 2015

21. Jensen MD, Ryan DH, Apovian CM, Ard JD, Comuzzie AG, Donato KA. Obesity Society. 2013 AHA/ACC/TOS guideline for the management of overweight and obesity in adults: a report of the American College of Cardiology/American Heart Association Task Force on Practice Guidelines and The Obesity Society. Circulation, 2014:129(25 Suppl 2), S102-S138. DOI: https://doi.org/10.1161/01.cir.0000437739.71477.e e

22. Dombrowski SU, Avenell A, Sniehott FF. Behavioural interventions for obese adults with additional risk factors for morbidity: systematic review of effects on behaviour, weight and disease risk factors. Obesity facts. 2010;3(6):377-96. DOI: https://doi.org/10.1159/000323076 